\title{
Ionic Liquid-Assisted Extraction of Essential Oils from Thujopsis dolobrata (Hiba)
}

\begin{abstract}
Aisya Syahmina and Toyonobu Usuki*
Department of Materials and Life Sciences, Faculty of Science and Technology, Sophia University, Tokyo, Japan

Corresponding author: t-usuki@ sophia.ac.jp
\end{abstract}

\section{Contents}

S2: GC-MS chromatograph

S3: IR spectra

S4: NMR spectra 


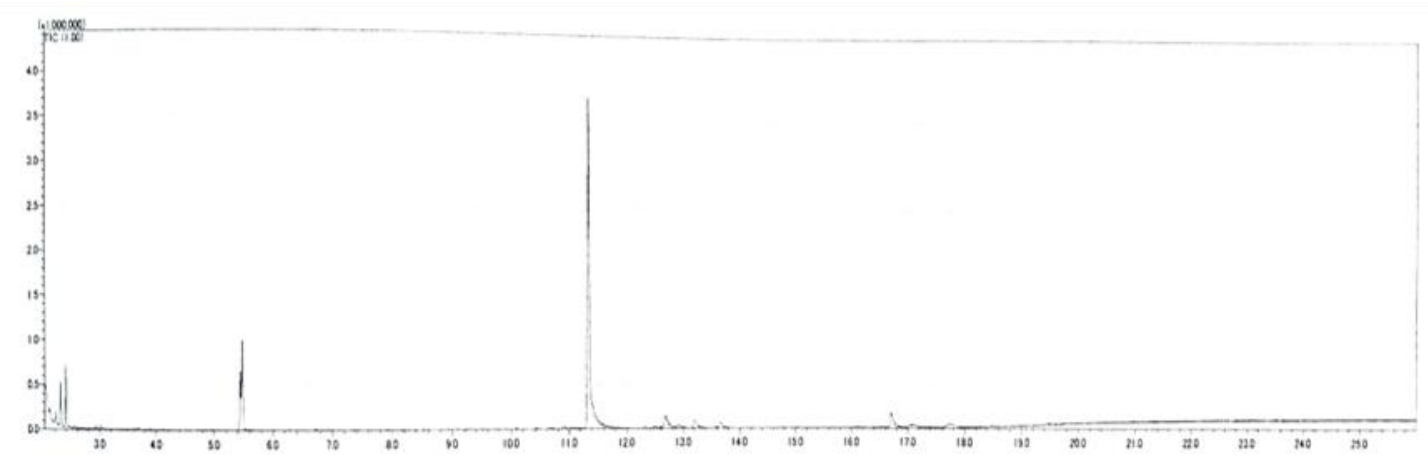

Figure S1. Chromatogram of hiba wood essential oil with internal standard (IS) limonene (5.5 $\mathrm{min})$. (-)-thujopsene and cedrol eluted at $11.3 \mathrm{~min}$ and $16.7 \mathrm{~min}$, respectively. 

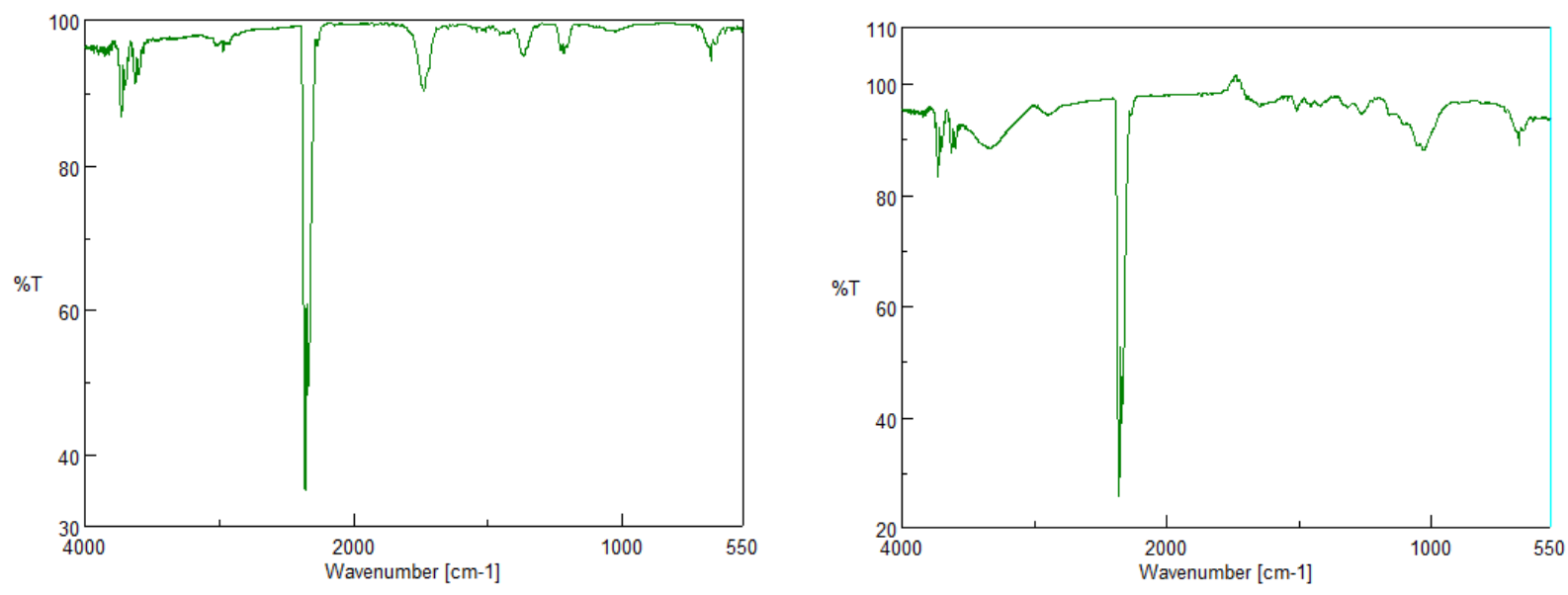

Figure S2. FT-IR of regenerated lignin (left) and cellulose-rich material (right). 


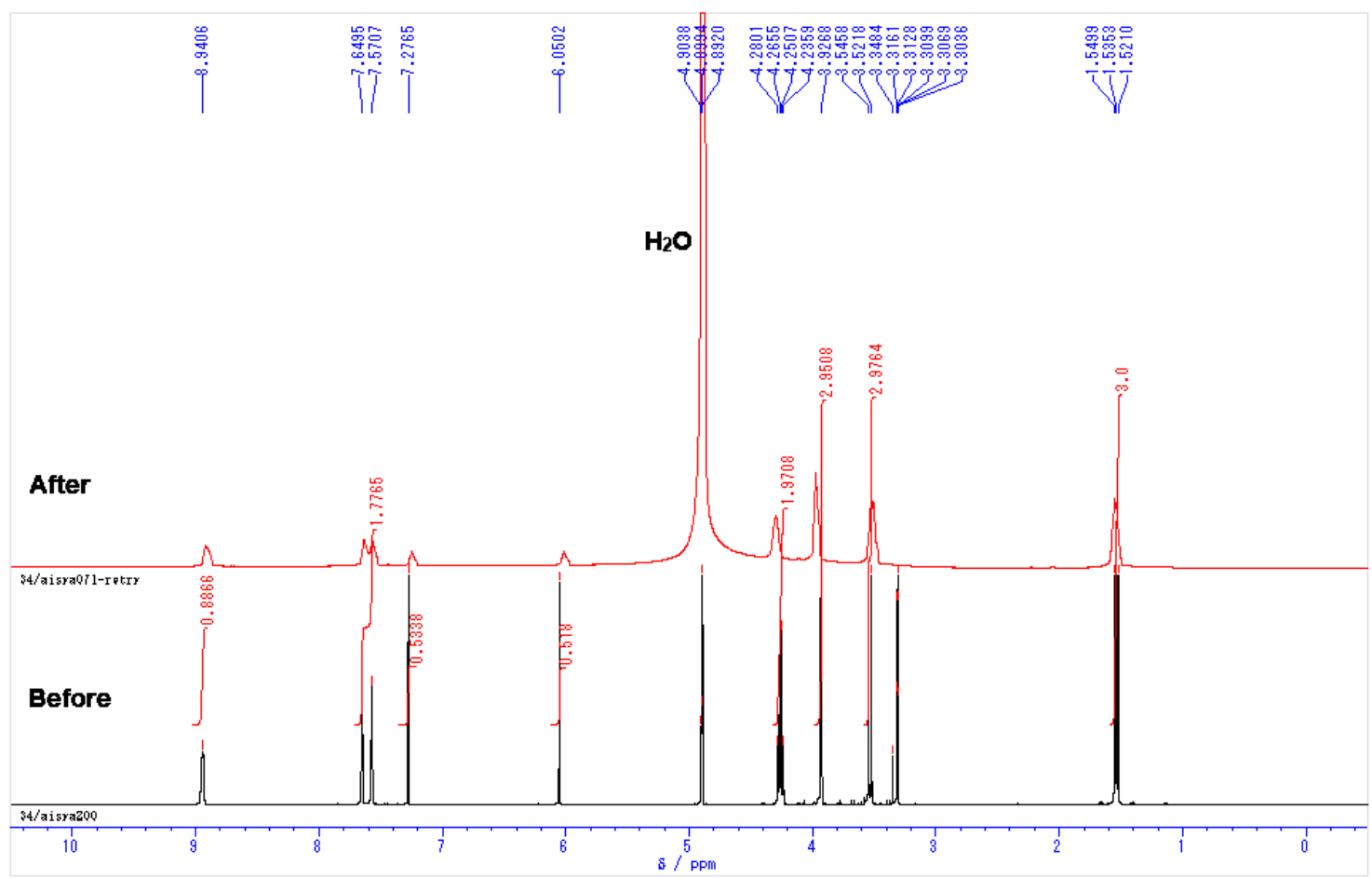

Figure S3. ${ }^{1} \mathrm{H}$ NMR $\left(500 \mathrm{MHz}, \mathrm{CD}_{3} \mathrm{OD}\right)$ comparison of $\left[\mathrm{C}_{2} \mathrm{mim}\right]\left[(\mathrm{MeO})(\mathrm{H}) \mathrm{PO}_{2}\right]$

before and after being used for extraction. Assignment $(\delta): 8.94(1 \mathrm{H}, \mathrm{s}, \mathrm{CH}), 7.65(1 \mathrm{H}, \mathrm{s}$, $\mathrm{NCH}), 7.57(1 \mathrm{H}, \mathrm{s}, \mathrm{NCH}), 6.66\left(1 \mathrm{H}, \mathrm{d}, J_{\mathrm{P}, \mathrm{H}}=613.2 \mathrm{~Hz}, \mathrm{PH}\right), 4.26(2 \mathrm{H}, \mathrm{q}, J=7.4 \mathrm{~Hz}$, $\left.\mathrm{CH}_{2}\right), 3.93(3 \mathrm{H}, \mathrm{s}, \mathrm{MeN}), 3.54(3 \mathrm{H}, \mathrm{d}, J=12.0 \mathrm{~Hz}, \mathrm{MeO}), 1.53(3 \mathrm{H}, \mathrm{t}, J=7.3 \mathrm{~Hz}, \mathrm{Me})$. 